International Journal of Industrial Engineering Research and Development (IJIERD)

Volume 8, Issue 2, May-December 2017, pp. 5-14, Article ID: IJIERD_08_02_002

Available online at https://iaeme.com/Home/issue/IJIERD?Volume $=8 \&$ Issue $=2$

ISSN Print: 0976 - 6979andISSN Online: 0976 - 6987

DOI: https://doi.org/10.34218/IJIERD.8.2.2017.002

(C) IAEME Publication

\title{
KNOWLEDGE MANAGEMENT AND BIG DATA: OPPORTUNITIES AND CHALLENGES FOR SMALL AND MEDIUM ENTERPRISES (SME)
}

\author{
Patrick Mbassegue \\ Ecole Polytechnique, Montreal, Canada \\ Ma-Lorena Escandon-Quintanilla
}

Ecole de Technologie Superieure, Montreal, Canada

Mickael Gardoni

Ecole de Technologie Superieure, Montreal, Canada

National Institute of Applied Sciences - INSA, Strasbourg, France

\begin{abstract}
Whenever a new technology is made available, it is worth finding possible uses in different domains. The advancement of information technologies now enables a wealth of information to be digitally collected and exploited for knowledge management and reused for further knowledge creation. Big data enables organizations to capitalize on large amounts of data by bringing together different sources of information to find trends and knowledge that are only visible with large amounts of data. This knowledge can then be applied for knowledge exploration, exploitation and decision making.
\end{abstract}

Keywords: knowledge management, big data, data analytics, SME, small medium enterprises.

Cite this Article: Patrick Mbassegue, Ma-Lorena Escandon-Quintanilla, Mickael Gardoni, Knowledge Management and Big Data: Opportunities and Challenges for Small and Medium Enterprises (SME), International Journal of Industrial

Engineering Research and Development, 8(2), 2017, pp. 5-14.

https://iaeme.com/Home/issue/IJIERD?Volume $=8 \&$ Issue $=2$

\section{INTRODUCTION}

Knowledge management allows companies to make the most out of the information they collect and generate. However, it relies on an ongoing effort by companies to keep their records, and process them continuously. It requires dedicated resources to explore the information generated outside organizational borders to remain competitive and be able to react to environmental changes. 
New information technologies now make it possible to build a knowledge based which can include internal and external information, and provide insights and knowledge which can only be detected when large amounts of data are being studied.

In this paper, we discuss the link between big data tools and techniques and how they can support a knowledge management effort in a small or medium enterprise, as well as the challenges they might face when undergoing such efforts.

\section{BIG DATA AND MANAGERIAL IMPLICATIONS}

\subsection{The Concept of Big Data}

Big data stems from our current ability to generate exponential volumes of data. Data is everywhere and growing at an exponential rate (Lynch, 2008 [1]; Tweed, 2013 [2]; Delort, 2015 [3]). It comes from individuals, groups, organizations, networks, connected objects, etc. (McKinsey, 2011 [4]). However, it is necessary to find ways to make data more accessible (Dove \& Jones, 2014 [5]).

The current threshold of a big data set is about an exabyte, or a quintillion bytes" (Howkins, 2002 [6]). Nonetheless, Howkins (2002) [6] explains that the criteria for big data is not only the size, but the variety in the data, the potential relationships between the data and the need for new tools to be able to exploit the data (see also Maniyka et al., 2001 in Kabir \& Carayannis 2013) [7]. Because data can be reused and analyzed in different ways to find new insights, companies need to take advantage of the wealth of data by using it in a more creative fashion (Howkins, 2002) [6].

The produced data is distinguished by a number of characteristics, also known as the $5 \mathrm{Vs}$ : volume, variety, velocity, veracity and value (Laney, 2001 [8]; Koutroumpis \& Leiponer, 2013 [9]). The combination of these characteristics shows the richness they entail for organizations, especially for decision making.

The data also allows for a more precise understanding of phenomena and the discovery of relationships that exist between variables; to not only identify the linear causalities, but also the cross-effects between the variables involved in an observed phenomenon (Beyer \& Laney, 2012 [10]). Indeed, we not only try to understand what happens at time t, but also to identify the trend and what will materialize at $t+1$. The predictive dimension, and consequently an ability to manage uncertainty, is sought: what is beneficial to the manager to successfully accomplish the primary tasks of management: plan, organize, manage, and control (POMC).

\subsection{Big Data Needs SMEs}

For organizations, the presence of this much data represents a challenge, as well as potential new opportunities (George and al., 2014 [11]). Consequently, SMEs face the same challenges and issues as large organizations concerning the need for information, to process it, and use it to make decisions. In this sense, SMEs are subject to a large volume of internal data (which they generate and / or collect) just as much as external (data produced in their specific industry, as well as for the overall business ecosystem). The data affecting SMEs is increasingly large; they are collected in real time from various sources (Liebowitz, 2013 [12]; Tweed, 2013 [2]). For SMEs, the imperatives of Big data are situated in 3 levels: internal environment, external environment and organizational performance.

Internally, SMEs are structured in different departments or functions, each of which generate and collect important volumes of data, but different in nature. For example, the data generated and collected in marketing department is different from the data in production, 
finance, human resources or supply management. All these data are necessary and essential to generate value (Delport, 2015 [3]). SMEs need an infrastructure adapted to optimally exploit its data; in that way Big data attributes can reconcile all these disparate data and enable their processing on a common basis. It enables the optimization of exploitation activities.

The daily management practices show that the diversity of functions and data induces a managerial structural division which has a negative impact on the quality of decisions. However, the functions that make up the organizational structure are the basis and the architecture that enable SMEs to offer products and services customers expect.

Externally, SMEs are found in an environment that creates pressures to which they must develop adaptation strategies and solutions. However, this environment produces an exponential amount of data on different levels based on economic, political, competitive, technological, social and demographic variables (McKinsey, 2011 [4]; George and al., 2014[11]). To ensure its survival and especially improve its competitive position, SMEs must collect, process and integrate external data in decision making.

The market competition has expanded and is not limited by geographic boundaries; therefore, ignoring it will contribute to weaken the basis on which decisions are taken by SMEs. Moreover, the consideration of a large and diverse volume of data enables a better understanding of customers, the quality of the service provided, and its relevance to each of the specific groups of consumers. Thus, based on a critical mass of diverse data, external to the organization, SMEs can better understand its ecosystem, environment and offer products and services that serve its various market segments (Chan, 2014 [13]; George and al., 2014 [11]).

Based on these environmental constraints, SMEs need to consider all the data at their disposal, both to optimize the foundation of its operations and the combination of its internal resources to improve its external position and its ability to provide the answers needed by its clients.

\section{KNOWLEDGE MANAGEMENT AND MANAGERIAL IMPLICATIONS}

\subsection{Knowledge Management Concept and Activities}

The concept of KM or knowledge management is subject of different representations, particularly among sociologists (Latour, 1987 [14]), philosophers of science (Polanyi, 1966 [15]), economists (Winter \& Nelson, 1982 [16]), industrial economists (Porter, 1987 [17]), promoters of knowledge engineering (Tarondeau, 1998 [18]; Ermine, 2000 [19]) and strategic management (Wernerfelt, 1984 [20]; Barney, 1991 [21]; Wright \& Van Wijk, 1995 [22]). Despite these differences, it appears that knowledge becomes a source of income that allows a firm to stand out in its market or markets. Therefore, knowledge prevails as much at individual and collective levels (service, department, division) as at an organizational level (Lebowitz, 1999 [23]; Alavi \& Leidner, 2001 [24]).

Knowledge management activities correspond to different organizational aspects, namely managerial practices, material and technical structures that enable the identification, processing and dissemination of knowledge (Veybel \& Prieur, 2003 [25]; Ling, 2011 [26]). In this case, we are talking more of a global knowledge management that takes into account different aspects namely: 1- The implementation process of activities, material and organizational infrastructure; 2- From which the players in the organization develop collaborative relationships, partnerships and exchanges; 3- The development, coding, 
creation, acquisition, storage, processing and use of knowledge; 4- By relying on human relations and organizational support, relationship, material and technology.

The overall management of knowledge should lead to a situation that favors organizational performance. The latter is generated by the emergence of a new culture and practices based on the exploitation of organizational knowledge. KM also allows the organization to eventually build a competitive advantage and improve or maintain its competitive position.

Managers then have the mandate to build the organizational capacity to develop a competitive advantage that is materialized by a better competitive position. Knowledge thus becomes a matter of strategic interest. The resources mobilized by the organization must allow the creation of value in a context of increasingly competitive markets. To do this, managers must seek different ways to promote the creation of value; it is necessary to master and apply individual and collective intelligence based on the combination of available knowledge. $\mathrm{KM}$ is therefore one of the critical ingredients to create value, especially in today's economy which is increasingly intangible and service based.

\subsection{Knowledge Management and Needs for SMEs}

$\mathrm{KM}$ is recognized by many as a framework of choice for organizations to create value: What about small and medium-sized enterprises (SMEs)? SMEs, beyond their relative weight in the ecosystem, are characterized by other dimensions. They are generally small in size and concentrated in specific market segments (Marchesnay and al., 1990 [27]). Their income depends on a limited number of market segments, products or services, makes them especially vulnerable. There are less diversified than large organizations (Julien, 2002 [28]). All these dimensions weaken the SME.

Furthermore, management is often concentrated in the hands of the founder who also serves as senior manager or CEO. The CEO not only has the authority because he or she controls the capital, but also the legitimacy of being the founder (Julien, 2005 [28]; OCDE, 2005 [29]). Because of its position and its multi-dimensional role, the place of the founder is critical. The success and performance of the SME will depend on his/her potential, abilities and knowledge.

In terms of management practices, it appears that the strategic fragility of the SME is also characterized by the practice of solving problems day to day without relying systematically on previous experiences (Asmaa, 2010 [30]). Thus, the accumulated experiences held by the few employees who are part of the SME may not be taken into account.

In the SME, all structural features related to production or service delivery system predominate. But what characterizes the organizational performance is the structural balance between structure strategy and the ability of leaders to take into account the dynamics of the environment by offering answers (products or services) expected by potential customers.

Indeed, based on the findings relating to the SME management practices, $\mathrm{KM}$ is an indispensable framework to be effective and efficient. Effectiveness is induced by KM to the extent that identification activities will help better identify the needs of clients. Efficiency is induced by the capitalization of both internal and external knowledge. The capitalization of knowledge contributes to the optimization of the resources mobilized to provide products and services. This optimization of resources also has an impact on the costs of goods and services, because based on the capitalization and enhancement of knowledge it is possible to find innovative solutions to improve quality and productivity (Mbassegue and al., 2015 [31]). 
$\mathrm{KM}$ for the SME is critical because it will help adopt management practices that will allow combining all critical resources, namely its processes and knowledge. Building a collective and organizational intelligence, permitted because of $\mathrm{KM}$, promotes the emergence of shared practices of assimilated knowledge, mastered and produced by all actors of the SME.

\section{THE BASIS OF KNOWLEDGE MANAGEMENT AND BIG DATA INTEGRATION}

\subsection{Association of Knowledge Management and Big Data: Strategic and Operational Necessity}

Starting with Nonaka and Takeuchi (1995) [32], the domain of Knowledge Management has been engaged in researching the way knowledge is created and transmitted within companies. This domain evolved to include the adoption of computer systems to support different aspects of KM. KM is at the service of the organization, particularly for value creation. In this sense, it's important to characterize knowledge management activities and big date dimensions to find a common base for integration. On one side, knowledge activities means identify, capture, store, analyze, disseminate, share and develop new solutions and innovative solutions which contribute to this creation of value. On the other side the characterization of Big Data is established from 5 dimensions (volume, velocity, variety, veracity, value), which are necessary to the creation of value (Laney, 2001 [8]).

The combination of $\mathrm{KM}$ and Big data is necessary because of the reality of SME management and the inputs for basic value creation. The base of KM is about to manage knowledge. Therefore, knowledge cycle is characterized by three elements: the data, which when contextualized becomes information, and in turn information becomes knowledge when processed. Data is therefore the first material from which we arrive at knowledge of different kinds, following the application of various transformational knowledge (algorithms, artificial intelligence base, etc.) recognized as the basis of analysis (or analytics) and treatments made with the support of information technologies (Sathi, 2012 [33]; Minelli and al., 2013 [34]). The achieved knowledge is usable, structured and, mostly, generates value for the organization. This whole cycle embodied elements from Big data characteristics and dimensions relating to KM activities which in fine contributes to the global performance of the SME (Figure 1).

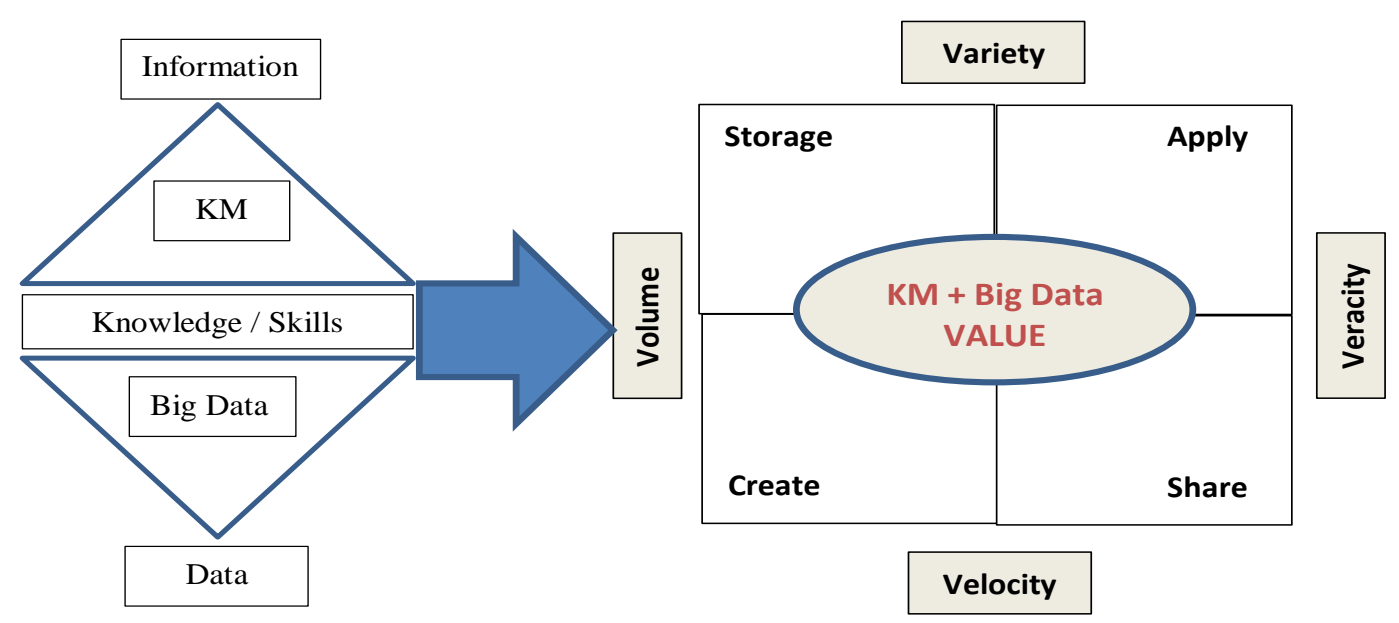

Figure 1. Integration of KM and Big Data 
Conceptually, the model of the processing chain (income, input, throughput, output, outcome) is as relevant in situations of $\mathrm{KM}$ as Big Data. Indeed, this conceptual model helps to understand how the SME identifies needs it wants to respond, what resources to mobilize and the products and services to offer in this regard. For this model to materialize in an effective performance, the data collected must be important, varied, voluminous, and collected in a systematic manner. The SME will develop effective processing capacity of inputs into outputs, with the purpose of creating value. Including large quantities of data nourishes the process level activities: that which characterizes the nature of KM as well as Big Data (Bose, 2009 [35]).

Moreover, whether at the beginning of the organizational value chain model (income, input), for processing (process), or at the outlet (ouput, outcome), the need for large quantities and varied data is necessary so managers can take on the challenge that is theirs, namely achieving arbitrations that will lead to the optimal allocation of scarce resources, and to create value. This is the real result sought by the SME when implementing initiatives combining KM and big data (Rothberg \& Erickson [36], 2005; Sathi, 2012 [33]).

Baesens (2014) [37] underlines others aspects of the link between knowledge management and big data. Figure 2 depicts this analytics process. In this model, the first step is the gathering of data from different sources, followed by the data selection, cleaning and transformation, to provide users with the data analyzed in patterns. It is up to the users to obtain insights from the patterns.

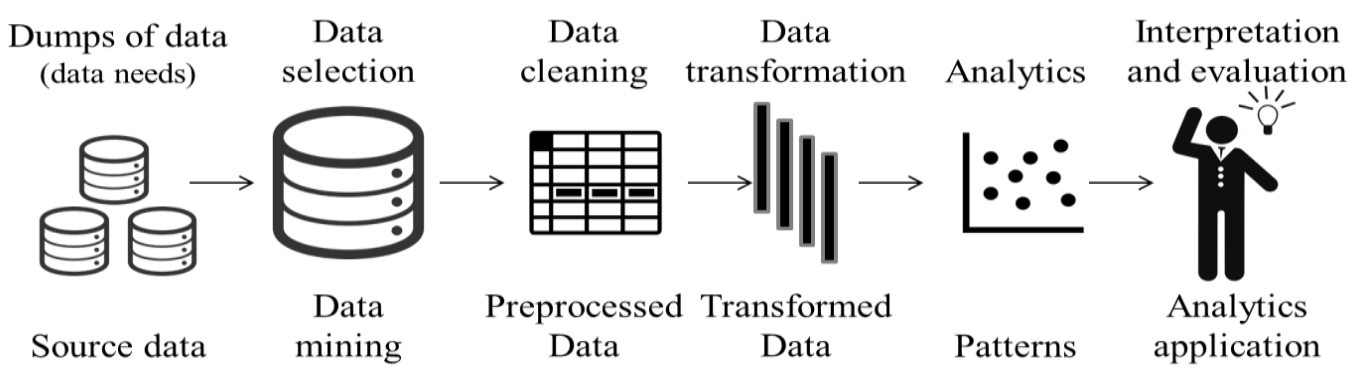

Figure 2 The analytics process model (Baesens, 2014)

In sum, these dimensions are functionally nested in each other. Data mining, processing and transformation will lead to the discover patterns and structures that can make sense of the data. Because there are different types of data, a greater volume means more matches, which will rich the potential application and exploitation (Bose, 2009 [35]; Erickson \& Rotheberg, 2014 [38]). To succeed in this operation and the extraction of value in the data, it takes knowledge or prior knowledge. Big data provides the necessary variety and especially appropriate analytical tools to make a more efficient organization by setting in place an initiative to treat and exploit diverse data.

\subsection{Potential Benefits of the Knowledge Management and Big Data Integration}

Benefits stemming from the combination of KM and Big data can be assigned to three key activities: knowledge exploitation, knowledge exploration and decision making. We talk about exploitation when we discuss the efforts in an organization to take advantage of internal resources to improve the solutions offered. In using KM to exploit internal resources, the effort of linking it with Big data could result in a better understanding of the current market segment. In turn, this understanding can be applied to:

- Improve current users' satisfaction

- Build a knowledge base from previous product development efforts 
Knowledge Exploration refers to the activities performed by an organization to find out about knowledge outside the frontiers of the company. It means keeping track of competitors, news, research and trends that might affect their operations. By including external data sources as an input for the organizational effort of combining KM and Big data, the insights of this exploration can lead to:

- The identification of potential new products / services

- The identification of complementary resources (opportunities for collaboration, new suppliers)

To make decisions, organizational leaders need to rely on different variables (sales, income, number of customers, customer geography, market segments, employee skills and productivity, etc.). In practice, however, managers are limited to a few variables in their decision making process, ignoring the wealth contained in the important volume of data available to them. Big data processes, infrastructure and attributes, combined with the relatively low cost of data processing thus pave the way for new business models that are available to organizations, especially SMEs with limited resources which could take advantage of better business opportunities.

\section{CHALLENGES AND FUTURE WORK}

The challenges faced by SME concerning the integration of knowledge management activities and big data occurred at two levels, namely on data and organizational basis.

\subsection{Data Challenges}

External data comes from different sources, including social networks, connected objects, research publications, and institutional databases. This impressive production of available data is as much a threat as it is an opportunity.

A great challenge for SMEs is being able to maintain their data sources up to date, and to have access to external data which is behind a pay-wall. Social media companies have understood the value of data and, thus making it difficult for smaller companies to access social media information. Patents are also usually not easily accessible. A way for companies to access this data is to find a vendor from which to license an access to only the information it requires.

A second challenge related to data is the processing of the information. Once the company has surmounted the access challenge, it must then be able to define the right process to be performed on the data. Since resources are scarce in SMEs, the organization has two options to do this processing, assign an internal resource, or resort to a provider. Both options have advantages and disadvantages. Having an internal resource means that the organization can experiment with the questions it wants answers to, but it is a constant expense. Having a provider will drive the managers to figure out the questions before commissioning the development, but the company can profit from professionals who might be able to gear them in new directions.

A third challenge in terms of the data is the insight. As mentioned before, the data is useful when it is being interpreted by someone who has sufficient knowledge of the domain to be able to understand and read the weak signals that can indicate a new trend.

\subsection{Organizational Challenges}

It is necessary that the different functions are effective and efficient and contribute to organizational performance. The fact is that operations are so predominant, that there is a tendency to put limited resources to other functions, including client management, promotion, 
market segmentation, etc. But the need to create value leads the SME to use the knowledge from all functions.

To be able to profit from it, processing these data requires systematic collection, and a consistent information infrastructure. The purpose is to give a dynamic character to the data and to highlight the evolutionary aspect.

\subsection{Future Work}

To better evaluate the efforts implemented in SMEs to combine big data with knowledge management, the first step is to identify the kind of project the organization want to put in place in a short term period and long term. More than that, SME must be able to establish the link between these projects and the performance of the firm. The purpose is to understand practically how the integration of big data and knowledge management activities contribute to the organizational performance. To do so, we plan to conduct a survey with SME.

The results of the survey will provide an insight to the measures taken and the considerations regarding internal and external data, as well as the strategies to manage the knowledge base (in-house versus outsource of information systems).

\section{CONCLUSIONS}

SMEs interested in gaining insights and knowledge from internal and external information can turn to new technologies such as big data. The use of this technology will enable the organization to improve their competitiveness by figuring insights in the weak signals of future trends. The knowledge attained from these efforts can lead to the identification of new products, services and complementary resources.

Nonetheless, many aspects need to be taken into account in the implementation of such an initiative. Considerations regarding the data to be analyzed must be taken into account, as the data needs to be reliable. The new tools will allow size and speed of the data to not be a factor; it is the processing that will take center stage, asking the right questions is what will provide the advantage.

\section{REFERENCES}

[1] Lynch, C.: Big Data: How Do Your Data Grow? Nature, sept., vol. 455/4, p. 28-29 (2008) https://doi.org/10.1038/455028a

[2] Tweed, K.: Smart Meters Deliver 1 Billion Data Points Daily (2013). Retrieved March 29, from http://www.greentechmedia.com/articles/

[3] Delort, P.: Big Data. Collection What do I know? Paris: Puf (2015)

[4] McKinsey Global Institute: Big data: The Next Frontier for Innovation, Competition and Productivity. June, McKinsey \& Company (2011).

[5] Dove, G. and Jones, S.: Using Information Visualization to Support Creativity in Service Design Workshops Proc Service Design and Innovation Conference. (2014)

[6] Howkins, J.: The creative economy: How people make money from ideas. United Kingdom : Penguin (2002)

[7] Kabir, N., \& Carayannis, E.: Big Data, Tacit Knowledge and Organizational Competitiveness. Journal of Intelligence Studies in Business, 3(3), (2003).

[8] Laney, D.: 3D Data Management: Controlling Data volume, Velocity and variety (2001). Retrieved March 29, from https://blogs.gartner.com/doug-laney/files/ 
Knowledge Management and Big Data: Opportunities and Challenges for Small and Medium Enterprises (SME)

[9] Koutroumpis, P., Leiponen, A. : Understanding The Value of Big Data. IEEE Conference on Big Data. Sillicon Valley, CA, October (2013)

[10] Beyer, M.A., Laney, D.: The Importance of Big Data: A Definition (2012). Retrieved, April 3, 2016 from https://www.gartner.com/doc/2057415

[11] George, G., Hass, M. R., Pentland, A.: Big Data and Management. Academy of Management Journal, April, 57(2), 321-326 (2014)

[12] Liebowitz, J. (Ed.).: Big Data and Business Analytics. CRC Press (2013)

[13] Chan, J.O.: The Big Data Customer knowledge Management. Communications of the IIMA, vol. 14, no. 3 (2014). Retrieved March 31st, from http://scholarworks.lib.csusb.edu/ciima/vol14/iss3/5

[14] Latour, B.: Science in Action : How to Follow Scientists and Engineers Trough Society, Harvard University Press, Cambridge (1987)

[15] Polanyi, M.: The Tacit Dimension. New York: Anchor Books (1966)

[16] Winter, S. G., \& Nelson, R.: An Evolutionary Theory of Economic Change. Cambridge: Belknap Press (1982)

[17] Porter, M.E.: From Competitive Advantage to Corporate Strategy. Harvard Business Re view, May/June, 43-59, (1987).

[18] Wenerfelt, B.: A Resource-Based View of The Firm. Strategic Management Journal, no 5, 171-180, (1984).

[19] Barney, J.: Firm Resources and Sustained Competitive Advantage. Journal of Management, vol 17, no 1, 99-120, (1991).

[20] Liebowitz, J. (Ed.).: Knowledge Management Handbook. CRC Press (1999)

[21] Alavi, M., Leidner, D.: Knowledge Management and Knowledge Management Systems : Conceptual Foundations and Research Issues. MIS Quarterly, vol 25, no 1, mars, 107-136 (2001).

[22] Ling, L.S.: Defining Knowledge Management Activities from Information Communication Technologies (ICTs) Perspective. Journal of Organizational Knowledge, vol. 2011, 1-10 (2011)

[23] Marchesnay, M., Julien, P.A.: The Small Business as a Transaction Space. Journal of Entrepreneuship, vol. 2, 111 (1990)

[24] Mbassegue, P., Lado-Nogning, F., Gardoni, Mi. : A Conceptual Model to Assess KM and Innovation Projects: A Need for an Unified Framework. PLM Conference 2015. Doha, Qatar.

[25] Nonaka, I, Takeuchi, H.: The Knowledge Creating Company: How Japanese Companies Create the Dynamics of Innovation. New York: Oxford University Press (1995) 
[26] Sathi, A.: Big Data Analytics: Disruptive Technologies for Changing the Game. Boise: MC Press (2012)

[27] Minelli, M., Chambers, M., Dhiraj, A.: Big Data, Big Analytics: Emerging Business Intelligence and Analytic Trends for Today's Businesses. New Jersey: John Wiley \& Sons Press (2013)

[28] Bose, R.: Advanced Analytics; Opportunities and Challenges. Industrial Management \& Data Systems, vol. 109, no.2, 155-172 (2009)

[29] Baesens, B.: Analytics in a Big Data World. Hoboken: John Wiley \& Sons (2014)

[30] Erickson, S., Rothberg, H.: Big Data and Knowledge Management: Establishing A Conceptual Foundation. Electronic Journal of Knowledge Management, vol. 12. No. 2, 108-116 (2014)

[31] Vidhya Sivasailanathan, Prabhat Kumar, Dr. N. Manoharan and K. Lingeswaran, Alara Implementation and Knowledge Management in Nuclear Power Plants. International Journal of Advanced Research in Engineering and Technology, 6 ( 8 ), 2015, pp. 69 - 82 .

[32] S. Abdul Hameed and Dr. N. Shaik Mohamed. Knowledge Management and Organizational Performance in Engineering Organization. International Journal of Management, 7(2), 2016, pp. 183 - 190. 